\title{
Dose-response problem in testing the ventricular hypothesis: Reply to Myers and Cicero
}

ARYEH ROUTTENBERG, DEPARTMENT OF PSYCHOLOGY, NORTHWESTERN UNIVERSITY, Evanston, Ill. 60201

Myers \& Cicero (1968) have initiated experiments based on the proposal that certain components of carbachol-induced drinking may be mediated via the cerebral ventricles (Routtenberg, 1967). It is the purpose of this note to point out that their results do not warrant the conclusion that "drinking following the application of carbachol to any of a number of limbic structures is not mediated by the cerebral ventricular route" (p. 93).

The major result which Myers and Cicero take to support their conclusion is that carbachol injected into the ventricles did not produce drinking. On the surface this appears to be compelling evidence against the ventricular hypothesis. Examination of their procedure, however, reveals that these investigators employ a technique that is somewhat different from that typically used. Thus, most prior investigations have administered a small quantity of carbachol $(0.5-5 \mu \mathrm{g})$ in a single application, and then tested for the effects of such administration immediately after the single application for about a $1 \mathrm{~h}$ period. Myers and Cicero, on the other hand, employ a continuous infusion technique which leads to the application of no less than $12 \mu \mathrm{g}$ and as much as $78.6 \mu \mathrm{g}$ of carbachol in a $24 \mathrm{~h}$ period. Water consumption is measured every $24 \mathrm{~h}$.

It seems possible that the negative results obtained by Myers and Cicero may be related to the excessive amounts of carbachol applied, the consequent side effects of such amounts, and the masking of drinking behavior caused by such side effects. It is important, first, to note the results of Feider (1967) who reported that carbachol remains active at least $2 \mathrm{~h}$ after application of this substance. As the $2 \mathrm{~h}$ interval was the longest tested, and as there did not appear to be any appreciable decline at that interval, it is worth emphasizing "at least" since the upper limits have not been evaluated. The point of the Feider (1967) report for the present comment is that rather than producing a steady-state effect by continuous infusion, it may well be the case that in the Myers and Cicero study there was a continual build-up of carbachol over each successive $24 \mathrm{~h}$ period. Thus, even the lowest doses employed may have been quite excessive compared to the amount applied by other investigators. Such high doses might have elicited certain nonspecific factors that would have acted antagonistically to the drinking effect. That such might have been the case is suggested by the fact that in the Myers \& Cicero (1968) report there was a complete cessation of drinking at the higher doses of carbachol. such an obvious nonspecific effect might reflect a more subtle counteracting influence operating at lower dosage levels which was not sufficiently gross to notice without employing specific behavioral and physiological tests.

It should be pointed out, too, that other investigators have, in fact, obtained drinking by application of carbachol to the ventricle. Fisher \& Levitt (1967) found that carbachol applied to the ventricle at low doses produced drinking behavior, but that higher doses of carbachol did not. With regard to the problem of dose-response effects they note that "drinking following cholinergic stimulation is a low threshold response, easily masked (italics mine) by the effects produced by higher concentrations of the drug" (p. 840). This statement supports the suggestion made above that the negative results obtained by Myers and Cicero may be related to the application of too much carbachol.

My earlier comment (Routtenberg, 1967), called attention to the possible value of distinguishing between direct effects of carbachol on tissue immediately adjacent to the cannula tip, and indirect effects of carbachol transported to sites distant from the cannula. The result of Myers \& Cicero (1968) call attention to the fact that the injection of higher doses of carbachol will likely increase the difficulty of making such distinctions.

\section{REFERENCES}

FEIDER, A. Feedback control of carbachol-induced drinking. J. comp. physiol. Psychol., 1967, 64, 336-338.

FISHER, A. E., \& LEVITT, R. A. Drinking induced by carbachol: Thirst circuit or ventricular modification? Science, 1967, 157, 838-839.

MYERS, R. D., \& CICERO, T. J. Are the cerebral ventricles involved in thirst produced by a cholinergic substance? Psychon. Sci, 1968, 10,93-94.

ROUTTENBERG, A. Drinking induced by carbachol: Thirst circuit or ventricle modification? Science, 1967, 157, 838-839. 